\title{
The Role of Human-Computer Interaction (HCI) in Preventing the Excesses in Attracting Customers to E-Commerce
}

Ali Amkhani Samadi*

Department of Forest Information Technology, Eberswalde University of Germany, Schicklerstrasse, Eberswalde, Germany

\begin{abstract}
It is obvious that the progress of science and also the increase in working business and time restrictions have forced the human being to use the Internet networks and various personal computer systems in the world. Nowadays, the computers and the Internet networks have various applications in different aspects of human life; and the e-commerce is one of these applications which have caused dramatic changes in today's world. The e-commerce is considered as an efficient idea in optimal control of time and cost reduction and is welcomed by the governors and even the public; and its features are increasing day by day according to the competitive global environment. Therefore, the online sales organizations and websites are seeking to cover all or most of their activities in the forms of online services for customers through effective advertising. Moreover, the customers are looking for organizations and websites which are sufficiently reliable in order to build the infrastructures for their activities in the shortest time. In the field of e-commerce, the managers play effective roles in increasing the customer satisfaction, but unfortunately this science has become widespread in recent years and there are a lot of disorders and excesses by web designers in offering e-commerce services, so that some people are not willing to do their personal activities on the Internet due to overuse of advertising and provided service, and thus they have allocated their personal affairs to others and abandoned this technology over time. As the societies are now in progress, we should seriously take into account the factors which prevent this technology and should utilize the human-computer interaction $(\mathrm{HCl})$ science which is a method for optimizing the computer affairs in order to generalize it and prevent those factors. Accordingly, it is suggested including the $\mathrm{HCl}$ science in e-commerce activities and advertising in order to prevent the destructive excesses in this field.
\end{abstract}

Keywords: E-commerce; Information technology (IT); The internet, Website; Computer; Cyberspace

\section{Introduction}

The today's world is seeking to carry out its businesses at less cost and time, and with maximum efficiency; hence, the organizations and people are pursuing a common goal which is the high profitability for their activities. Therefore, the replacement of activities in cyberspace is the best method to do these affairs.

The cyberspace infrastructure for purchase and sales and provided services for companies and stores as the internet-based e-commerce allow the customers to search for information and purchase goods and services through direct connection with online stores. It should be noted that the online shopping is not based on the actual experience of buying the goods, but it is based on the aspects such as the image, shape, qualitative information and advertising of product [1].

The expansion of cyberspace has enhanced the competition between individuals and organizations, and thus the managers are seeking to find the ways which have more advantages than their competitors and this will be easier by providing broad and appropriate advertising.

Nowadays, the Internet is an important channel in marketing and advertising due to its potential for cost reduction and easy access to online services. Furthermore, the advertisers can easily access to multiple users and communicate with them at lower costs [2]. Meanwhile, despite the fact that the Internet has provided the efficient median for advertising, people are looking to maximize their investment in this category. Accordingly, several different studies have been conducted over time and various advertising models have been designed based on how people understand the internet advertising and what attitude they have towards it [3]. The low speed and cost of Internet advertising have increased its applicants and the volume of requests for advertising in cyberspace after a short time.

The speed of Internet advertising application is increased because the customers spend much online time on personal computers or use the other devices such as the mobile phones and TVs which have the ability to connect to the Web [4] hence, the advertising has quickly moved towards the online websites and search engines from dispersed on television and other methods [5]. Furthermore, due to the competition of websites because of the multiplicity in cyberspace, a variety of methods and probably the excessive method have been utilized to attract customers to e-commerce.

\section{E-commerce}

E-commerce is a process of buying, selling or exchanging goods, services and information via computer networks and the Internet [6]. The online shopping is done as a way to save the time of purchase compared to traditional shopping [7].

E-commerce has led to creation of virtual shops which have several advantages such as the convenience, competitive prices, wide selection, and access to further information. On the other hand, in the case of purchasing at home, the relationships and interactions between people will be minimized in the society [8]. In recent years, a large number of virtual shops have increased their communications with people via mobile pages and creation of virtual realities and online chatting [9].

Due to the increased communications and virtual networks, the

*Corresponding author: Ali Amkhani Samadi, Department of Forest Information Technology, Eberswalde University of Germany, Schicklerstrasse 5, 16225 Eberswalde, Germany, Tel: + 989357695707; E-mail: ali.amkhany@hotmail.com

Received January 29, 2018; Accepted February 27, 2018; Published March 05, 2018

Citation: Samadi AA (2018) The Role of Human-Computer Interaction ( $\mathrm{HCl})$ in Preventing the Excesses in Attracting Customers to E-Commerce. Review Pub Administration Manag 6: 239. doi:10.4172/2315-7844.1000239

Copyright: (c) 2018 Samadi AA. This is an open-access article distributed unde the terms of the Creative Commons Attribution License, which permits unrestricted use, distribution, and reproduction in any medium, provided the original author and source are credited. 
customers have fulfilled their personal needs by this method, and thus the companies and manufacturers have sought to offer their goods and services to customers in this competitive environment in order not to fall behind their competitors in domestic and foreign markets; hence, the number of advertising websites and personal and organization product introduction have been significantly increased in recent years.

From perspective of Peterson, the information technology (IT) has made much development in trade sphere and it is not because of its speed or easiness, but the spread of information technology and especially the internet creates the easy ability to go beyond the international boundaries, and thus the information transfer will be done regardless of geographic boundaries [10].

According to research by Rason et al. on the Internet and multinational small and medium-sized companies, the websites on the internet do not only means entering into the global markets. However, the most important point for companies is their ability to attract the target customers to their websites, and thereby encourage them to make their purchases via the Internet [11].

In the field of e-commerce, the online stores and companies should have the superior service tools such as the timely and quick delivery to customers, access to telephone support and facilities for product return and replace, and since there are not any sales employees in these stores, the customers should gain favorable experience of interactive shopping through tools such as clicking for telephone support and creating the chat rooms [12].

Due to the high competition in the e-commerce, the web designers and companies should pay attention to an important issue called the customers' easiness in doing their practices; in other words, it should be a beautiful design, fast search and provision of services with less cost and convenience than the other competitors.

Due to the intense competition in e-commerce at the local and global levels particularly on web pages and increased advertising on the cyberspace, different web pages are now full of excesses and abnormalities resulting from the lack of appropriate standards; and it has made problems for users. On the other hand, some people are non-reluctant to perform their daily activities on the internet and if it continues, it will slow down the progression of this technology due to the lack of customers' interest. This excess, which is often performed by web site admins, is as follows:

\section{Opened additional advertising pages}

Internet marketing is a form of marketing and advertising which uses the Internet to deliver promotional marketing messages to customers. It covers email marketing, search engine marketing, social media marketing, and numerous types of advertisement (such as the web advertising) and mobile advertising. Like other advertising media, online advertising often covers two subjects: a publisher who adds the advertising in the online content, and an advertiser who provides the advertisements, which should be displayed, for publisher. Other potential participants include advertising agencies which help to generate and insert the advertisement text; an advertisement server which technically delivers the advertisements and statistics; and the advertising affiliates who independently offer promotion for advertiser. Online advertising is a big business which is quickly growing.

Compared to the traditional advertising, online advertising has considerable advantages including the two-way communication with the audience, the relatively low cost, global and round-the-clock access, improved notification, easy updating, and accurate customer targeting [13].
Due to the revealed value of advertising on web pages over time, the webmasters have sought to earn more money through allocating larger volumes of designed pages to advertising. On the other hand, when the large and small companies and organizations found that the advertising imposes very low cost and numerous customers are present on cyberspace, a large volume of advertising was spread on the web pages and virtual networks.

Due to the increased number of advertising because of its numerous benefits over time, there are a few credible websites without advertising because it is considered as one of the best ways to earn money. In recent years, due to some corporate executives and website designers' greed for making money by this method, the service quality of numerous websites has been reduced because there are a few appropriate spaces for efficient designs; and the multiple advertising prevents performing a professional design.

Due to the advances in modern designs on web pages and virtual networks, the designers are able to accept a huge amount of advertising, so that we can see that some websites will show their whole advertising if you click on a link, and thus numerous pages unrelated to considered link and solely for loading the ads will be opened. Most of these numerous web pages which are opened for advertising, contain attractive sentences and pictures to persuade the customers not to close these pages and see their advertisement and use their service, but due to this insistence, the internet users have been bored of them and close the advertising pages without taking a look at them and some people are not willing to use some e-commerce services any longer.

\section{Mandatory memberships}

In the new era, called the world of information and communications, most of the organizations have sought to gather information about their customers in order to offer better services.

The customer information collection has helped the online sellers and organizations, and thus the webmasters are satisfied with their customer information, but recently the active websites in the field of e-commerce have extremely gathered the customers' information, so that they do not provide their services for users who are not the members of their websites; hence, the users who search on different search engines, have become tired of searching since most of the web sites have mandatory memberships, and thus refer to the internet cafes and other people to obtain the information.

Sometimes people register in web sites by filling the completely wrong information in fields in order to take the advantage of website services, so this damages the customer and company because on the one hand the expansion of such websites makes the customers confused due to the multiple registered information and different passwords and errors and this is a repulsion against the use of e-commerce science, and on the other hand, the companies will have the "value uncertainty", which means the lack of certainty about value of company, estimated by reasonable costs, due to the increased uncertain information [14].

The information theft is another important issue, with which the customers are obsessed in cyberspace; and it has made them uncertain about this technology; hence, they do not show much enthusiasm for mandatory memberships or continue writing false information as mentioned above.

\section{Misleading keywords}

Internet search means research on keywords via the online search engines in order to quickly and simplicity the vast and diverse amount of online information. 
Since the frequency of visiting a website will lead to the higher rank in search engines than other competitors, the designers are seeking to take the maximum advantage of it and invite numerous users to website, and also other get more money from the organizations and people who have requested for advertising on their web pages.

It has created greed in some designers and they often choose the keywords which are at the top of hot searches. The users search in engines and chose the target web pages, but he will not find his desired information when he visits those websites. This creates the "Internet Anxiety" in people. The Internet anxiety develops when people began to search for sources in order to achieve their goals and realize that do not have enough ability to accomplish this search. The characteristics of this anxiety are as follows: The negative feelings such as the doubt, stress, fear and mental disorders [15] and unethical action damages the use of e-commerce.

The problems above are some of the issues under which the people have stayed away from the e-commerce technology in today's society, and this is a big challenge; and if the webmaster and designers continues the same trend in advertising and providing their services, their customers will be reduced in the cyberspace, and even the wrong information received from their customers will make problems for their future planning. On this basis, the webmaster and designers are suggested using the HCI science, which is a new method in interaction between human and computer, in order to strengthen and develop the e-commerce; and thus, the international community will be developing in this technology as soon as possible, and its service will be increasing every day.

\section{Human-Computer Interaction (HCI)}

The human-computer interaction (HCI) refers to modern and diverse research knowledge and technology, design, implementation, and evaluation of computing systems involved in dialogue and interaction between human users and computers on the one hand, and the intelligent software factors on the other hand. This discipline is the science of investigating the human-computer interaction. In fact, this science is the point of intersection between the computer and behavioral sciences of design and several other sciences. Humancomputer interaction occurs via the interface which includes the software and hardware.

The main today's problem of computer technology is not related to issues between researcher, human and the environment, but it is also due to the deficiency in use of user- centered design methods. The main reason why today's technology does not seem appropriate for human routine use is not the failed HCI methods, but it is because they are rarely used; and if they are used carefully, the considerable success is achieved [16].

According to this description, due to the users and designers' lack of familiarity with this science, it has not been considerably used in advertising on virtual pages and websites design; hence, this issue should be taken into account by activists in the field of virtual world in order to introduce the human-computer interaction science not only in e-commerce, but also in other sciences.

The human-computer interaction (HCI) is primarily about design of useful computer systems including desktop computer, video, web, or mobile phone. It detects bad designs and provides strategies for improving them; and it also tries to apply their methods for initial design of good systems [17].

There is a need for completely different mindset in order to think about how to design, how to control and interact with ecosystem of emerging technologies, while most of the HCI researchers have begun to expand their perspectives; however, there is much work to be done. For instance, the HCI needs understanding and analyzing a larger set of issues which are currently used. We can prominently mention the human values which include the spiritual and moral aspects of new technologies designed. In other words, the long-term consequences, which may affect people, should be considered in designing the hardware and software [14].

\section{Discussion}

It is suggested that like the municipalities which are establishing order in construction of urban texture and pursue it in the real world, the HCI science should be introduced to designers in cyberspace in order to provide new and more efficient services according to their choices and this knowledge, because some of them have made mistakes and excesses in customer attraction and advertising. However, these excesses may be done unintentionally, but the introduced and strengthened $\mathrm{HCI}$ will enhance the e-commerce and other sciences in cyberspace. If this case is not ignored, the world assigns most of its affairs to it in the near future.

Therefore, as the designers consider the need for attracting advertisement and increasing their income, it is suggested that the organizational managers and them should pay attention to customers demands and more importantly their comfort in cyberspace in order to move ahead of other competitors and make their customers loyal, as the percentage of internet users, who find their favorite websites via direct navigation- which means entering a well-known URL in a browser is increasing and it is now more than the users who find their websites via the web links and search engines. (Stat market); and this is the evidence for customer attraction and their loyalty to a website.

\section{Conclusion}

Nowadays, the cyberspace is a place of confrontation between cultures and different individual ideas, so that everyone who is able to design the web pages, can do his favorite business on his personal web page, but sometimes the excesses and applied methods by some people in advertising and attracting the users will damage the virtual networks because its main basis as the Internet customer is not willing to contribute in them any longer. On this basis, the webmasters and designers who are willing to advertise for their organizations on web pages, should pay attention to customers' needs and culture, and put themselves in their shoes. This needs knowledge about different sciences and the HCT as one of the most perfect current sciences about the Internet and computer since it has been neglected in recent years. The designers are suggested utilizing the HCT and ethical methods for strengthening design and attracting the customers in order to build their trust which is one of the main principles in today's world.

\section{References}

1. Lohse GL, Spiller P (1999) Internet retail store design: How the user interface influences traffic and sales. Comput Med Commun.

2. Lages $L$ (2004) The STEP scale: A measure of short-term export performance improvement. J Int Market 12: 36-56.

3. Rodgers S, Thorson E (2013) The interactive advertising model: How users perceive and process online ads. J Interact Advert 1: 42-61.

4. Evans DS (2008) The role of economics in online advertising. Rev Netw Econ 21: $1-13$.

5. Kutty VN (2010) Accept reject decision in online advertising using geometric bromnian motion. 
Citation: Samadi AA (2018) The Role of Human-Computer Interaction ( $\mathrm{HCl})$ in Preventing the Excesses in Attracting Customers to E-Commerce. Review Pub Administration Manag 6: 239. doi:10.4172/2315-7844.1000239

6. Turban E, Lee J, King D, Chung HM (2010) Electronic commerce: Management perspective, Prentiice hall, USA.

7. Pamela A, Robert S (2003) Consumer perception of online versus store shopping.

8. Craig S (2000) Internet commerce development.

9. Paul T (2000) Electronic commerce: Strategies and models for business to business trading, Library of congress.

10. Hayek V (1934) Economics and knowledge, Economia

11. Alice K (2002) The internationalization of small and medium-sized enterprises (SMEs) and the impact of the internet universities Maastricht, faculty of economics and business administration, Maastricht.
12. Charles D, Tino F, Bill M (2004) E-retailing. Routledge, Taylor, UK.

13. Zohre DS, Nazila LN (2009) The effectiveness of Internet advertising on consumer behavior goods and computer services. J Manage Stud Exten 20: 124-114.

14. Rezvan $\mathrm{H}$, Rahele Q, Karimi MB (2011) Smoothing and uncertainty information. Stud Account Audit 18: 63

15. Abedi SK (2007) The electronic resources in the library anxiety and anxiety among university students. Educ Psychol 8 : 130-115.

16. Ali RS, Ebrahim R (2014) Look to the future of human computer interaction Comput Eng Technol Manage Conf.

17. Harper R Rodden T, Rogers $Y$, Sellen A (2008) Being human: Human-computer Interaction in the year 2020 ( $1^{\text {st }}$ edn) England: Microsoft Research Ltd. 